\title{
SYMPOSIUM
}

\section{governing renewable energy in the EU: confronting a governance dilemma}

roger hildingsson ${ }^{a, \star}$, johannes stripple ${ }^{a}$ and andrew jordan ${ }^{b}$

aEnvironmental Politics Research Group, Department of Political Science, Lund University, P.O. Box 52, SE-221 00 Lund, Sweden

E-mail: Roger.Hildingsson@svet.lu.se

bSchool of Environmental Sciences, University of East Anglia, Norwich NR4 7TJ, UK

${ }^{*}$ Corresponding author.

doi:10.1057/eps.2011.8; published online 24 June 2011

\begin{abstract}
Promoting renewable energy sources (RES) has been addressed a key strategy for mitigating climate change, the governing in which has turned out a challenging and protracted task for the EU. There is often an implicit assumption that concern for climate change drives energy policy, but a closer look at the development of European RES policy indicates how EU governors have had to confront a range of governance dilemmas in trying to balance various objectives and conflicting interests. Therefore, while energy security and environmental concerns have provided a rationale for crafting renewable energy as a specific EU policy domain, the main driver for RES policy coordination has been internal market concerns, and not the concern about an impending climate catastrophe. More recently, rising concerns about energy insecurity and climate change have forced the EU to seek greater policy coordination in the context of more integrated energy markets. Although seemingly propitious for further harmonisation, it is doubtful whether the Member States and their citizens are yet prepared to accept new efforts towards deeper integration of European energy policy.
\end{abstract}

Keywords EU; European governance; renewable energy sources; climate change; energy policy

$\mathrm{P}$ romoting renewable energy sources (RES) has been addressed as a key strategy for mitigating climate change, but governing renewable energy from Brussels is, to say the least, a challenge. ${ }^{1}$ Energy policy has traditionally been a matter of national control while mainly the responsibility for market liberalisation has resided at the EU level. Across Europe, EU Member States 
have employed different strategies and mechanisms to promote renewable energy technologies at varying stages of development. To make such a patchwork of national policies to work coherently and effectively is a daunting task. Indeed, the development of EU renewable energy policy has been a protracted one in which EU governors have had to confront a set of critical governance dilemmas in trying to balance between various objectives and conflicting interests.

The aim of this article is to capture the nature of promoting renewable energy as a governance dilemma for EU governors. Governing any policy problem requires political choices to be made between alternative courses of action. Choices have to be made about, for instance, the definition of the problem, aims and objectives, the appropriate political level to act on and which types of policy instrument to deploy. Drawing on Jordan et al (2010), who describe how such choices generate 'governance dilemmas', we investigate four types of dilemmas that have been critical for governing renewable energy in the EU. The first dilemma arises from the choice of what problem policy makers seek to address among all those that concern the public. Renewable energy has been articulated as the solution to the dependence on imported energy, to climate change and to market inefficiencies, but in the EU the relative salience of these problems have varied over time. The second dilemma relates to the choice of levels to act on, and we hereby describe a move from 'policy coordination' to 'regulatory harmonisation'. The third dilemma is about which modes and instruments of steering that are selected to address the problem at hand. In the widest sense, the choice here has been between efforts to push renewable energy technologies onto the market (through R\&D support) or to pull them into the market (through deployment support) and, further, between specific

\section{'...we investigate four types of dilemmas that have been critical for governing renewable energy in the $E U^{\prime}$.}

instruments. The fourth dilemma is about how to secure policy change and ensure compliance. The key choice here is about whether to enforce (sanctions) or to encourage implementation (informal instruments). In this respect, previous implementation deficits have paved the way for new enforcement measures in the current RES Directive.

The article is organised as follows. First we outline the historic development of European renewable energy policy in terms of five distinct phases. We then describe each governance dilemma in more detail and use them to illuminate the choices that have been made when striving to govern renewable energy in the EU. In the concluding reflections we look across the dilemmas to establish what have most affected the rationales behind crafting renewable energy as a specific EU policy domain.

\section{THE DEVELOPMENT OF EUROPEAN RENEWABLE ENERGY POLICY}

European renewable energy policy has been long in the making. It developed slowly from quite loose forms of cooperation in the 1980 s towards a common policy framework in the recent climate and energy package. Over time, the modes and means of EU coordination have evolved in a stepwise fashion that can be described in a series of different phases (see Table 1). The first phase coincides with the search for 'new energy 


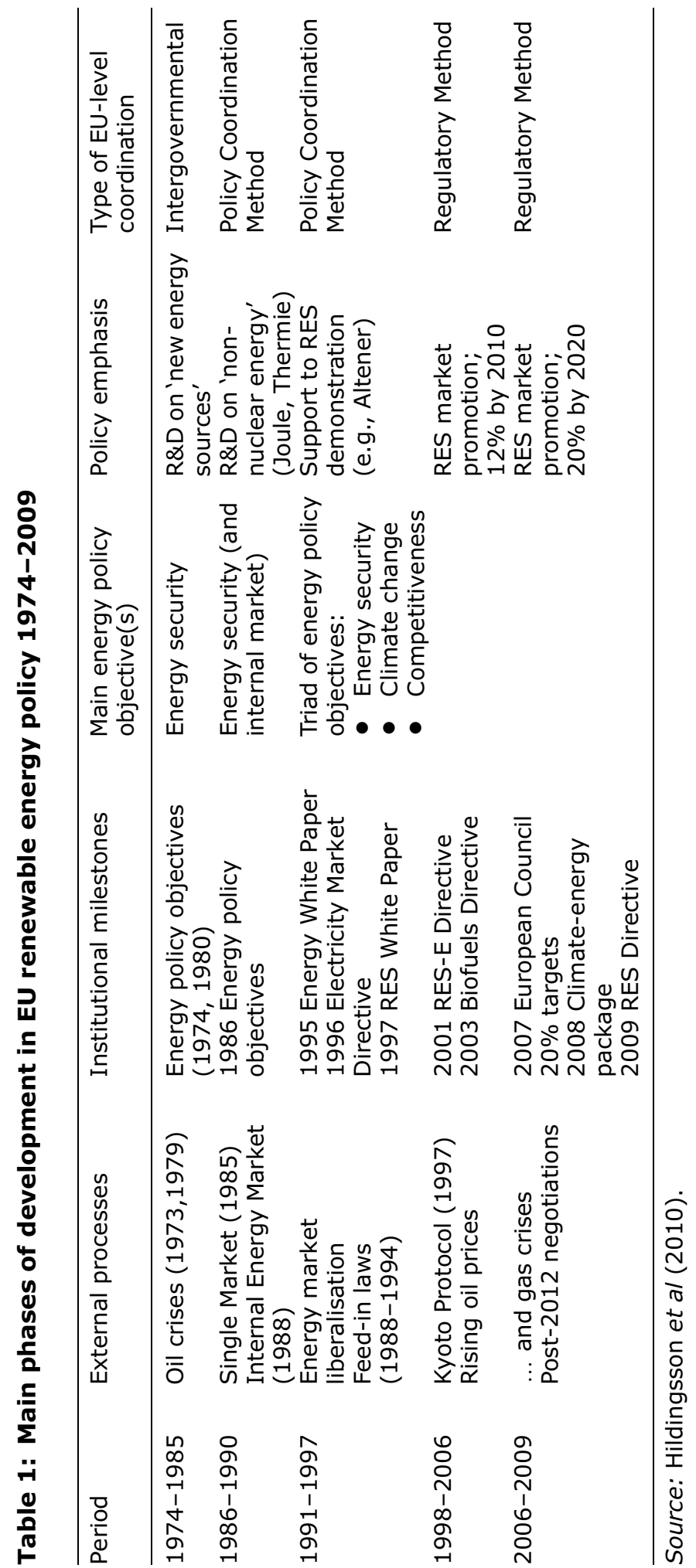

20 european political science: 112012 governing renewable energy in the EU 
sources' in the aftermath to the oil crises in the 1970s. The EC tried to exploit these supply-sided shocks to develop a common energy strategy, but did not succeed in attracting Member State support beyond very loose forms of intergovernmental co-operation, around a set of indicative energy security objectives. The second phase represents the establishment of renewable energy on the EC agenda in the late 1980s. In the 1986 revision of the community energy objectives (COM(85) 245) renewable energy was addressed as a policy priority for the first time. The Joule and Thermie programmes provided financial support to 'non-nuclear energies', but implied only a continuation of the previous soft coordination of research, development and demonstration (R\&D) policies.

In the third phase the first steps towards a common RES policy framework were taken. National energy policy shifted in the early 1990s from supporting $R \& D$ to promoting market deployment of renewable energy, particularly in 'pioneering states' such as Germany and Denmark. The first steps towards creating an internal energy market, and concern for the environment, called for EU-level action. The first specific EU-wide RES initiative, ALTENER (COM(92) 180), was introduced in 1993 with the aim to double the RES share by 2005 . However, since ALTENER lacked the character of a coherent strategy, merely providing support to demonstration projects, the European Parliament in 1995 called for an action plan to advance the EU's involvement (Lauber, 2005), and similar proposals were made in the Energy Policy White Paper (COM(95) 682). From this point in time, renewable energy came to be seen as a solution to a triad of issues: environmental and climate change, security of supply and economic competitiveness. The Commission outlined a common policy strategy in the 1997 White Paper Energy for the Future: Renewable sources of energy (COM(97) 599) that set out an indicative objective of doubling the RES share to 12 per cent by 2010 . Although the measures addressed to achieve this goal lacked legal underpinning, and thus remained an act of policy coordination, with hindsight this marked the birth of EU RES policy.

In the fourth phase, the policy strategy began its translation into a regulatory framework. After years of controversy, first the 2001 RES-E Directive (2001/77/ EC) and then the 2003 Biofuels Directive (2003/30/EC) set out targets for renewable electricity generation (21 per cent) and biofuels (5.75 per cent) by 2010 . The RES-E Directive established guiding principles on administrative procedures, 'guarantees of origins' (GO) and grid access, but settled for indicative targets instead of binding ones due to Member State opposition. During the preparations, the Commission also made efforts to harmonise national support policies, but this turned out to be deeply contested issue (Rowlands, 2005). While the Commission's preference for an EU-wide tradeable green certificate scheme was supported by some Member States (e.g., the UK), it was strongly opposed by others (e.g., Germany, Spain). A decisive moment was the ECJ final judgement on the Preussen Elektra versus Schleswag case passed in early 2001. The ECJ concluded that feed-in tariffs did not violate EU State Aid rules, which forced the Commission to tone down its support for tradeable certificates for the time being (Rowlands, 2005; Lauber, 2005; Johnston et al, 2008).

The fifth phase is about the establishment of the current regulatory framework that aims at increasing the total RES share to 20 per cent and to raise the proportion of transport biofuels to 10 per cent by 2020 . In January 2007, the Commission proposed these new RES targets and addressed regulatory initiatives in the Renewable Energy Roadmap 
$(\operatorname{COM}(2006)$ 848). At first, when the European Council approved the 20 per cent target (March 2007), the principle of differentiated mandatory targets was largely undisputed. But a year later, the inclusion of binding national targets in the draft RES Directive (COM(2008) 19) proved highly contentious. Apparently, basic disagreements over the harmonisation of national policies were still not resolved (Toke, 2008). Some states, notably the UK, again pressed for flexible implementation mechanisms such as trade in GOs, but were once more opposed by others. In the final Directive (2009/28/EC), a compromise was reached, providing for flexible co-operation mechanisms in terms of interstate 'statistical transfers', that is, permitting those states exceeding their indicative targets to transfer their surplus to others, as well as joint projects and support schemes. As the attempts to introduce a GO trading regime were unsuccessful, 'guarantees of origins' are thus only eligible for disclosure in target accounting, not for cross-border trade (Nilsson et al, 2009). Controversy also surrounded the sustainability criteria for biofuels. Despite fierce opposition from NGOs and in the European Parliament, the biofuels target subsisted. But in response to the addressed problems associated with first-generation biofuels (i.e., bioethanol, biodiesel), priority was given to secondgeneration biofuels, electric and hydrogen vehicles. At time of writing, Member States are about to submit their national renewable energy action plans as required in the new directive. In the forecast documents recently submitted (European Commission, 2010), Member States project to slightly overachieve the 20 per cent target by 2020 , with some states anticipating a surplus and others a deficit. This indicates at least some room for the new co-operation mechanisms. Therefore, although the Commission did not succeed to harmonise national
'...RES Directive permits bottom-up coordination but it does not harmonise national policies any further'.

policies any further, the RES Directive will permit bottom-up coordination.

\section{CONFRONTING GOVERNANCE DILEMMAS}

A 'dilemma' is usually defined as a situation in which one must choose between equally unpleasant alternatives. Jordan et al (2010) use the concept to draw attention to the political choices that are inherent in the art of governing a particular issue or domain. These are, for example, choices about the definition and framing of problems, the appropriate levels and scales of governance, the selection and calibration of different policy instruments, the distribution of costs and benefits among the governed and the mechanisms for ensuring implementation and compliance. As these choices involve values that are seldom commensurate and are subjected to time constraints, they normally entail governance dilemmas to which there are no easy solutions. The fact that various actors being governed typically subscribe to different framings of 'the problem', and vary in their perceptions of equity, effectiveness, transparency and democracy, makes the governance of something as renewable energy immensely difficult. If governing involves making difficult choices within a set of institutionalised structures, we need to know what kinds of choices these might be. Here, we investigate four particular types of dilemma that are prone to be critical for governing renewable energy in the EU. 


\section{WHY GOVERN RENEWABLE ENERGY: AUTONOMY, CLIMATE CHANGE OR MARKET EFFICIENCY?}

Governing is a purposive activity, but precisely which problems does it seek to address? 'Problems' are never simply 'out there' but are presented as a result of social processes in which actors engage in struggles to frame particular phenomena into problems that suit their political interests or policy competences. Policy makers often find themselves drawn to particular problem framings because they appear to fit with the way in which they are confronting other problems. This in turn raises yet more issues. For example, who is deemed responsible for the emergence of particular problems? Have governors deliberately promoted it or was it an unforeseen outcome of their otherwise legitimate activity? Once the choice about the nature of the problem, and hence the purpose of governance, have been identified, other choices quickly loom into view.

Governing renewable energy in the EU relates to how problem framings have changed over time and the impact this has had on the formulation of policy objectives. In the early years of the EU, the development of nuclear power capabilities secured a great deal of political attention. However, the energy crises in the 1970s triggered a search for alternative sources of energy including renewables. At this point, securing affordable energy supplies was the overriding problem frame, while environmentalists sought to draw attention to the potential future role of RES. This conflation of energy security and rising environmental concerns was briefly conducive to the early development of RES, but mostly they were viewed as an adjunct to nuclear power, domestic coal and natural gas. In the 1990 s, some states began introducing carbon taxation to promote energy performance and RES deployment, but falling energy prices did weaken the case for RES investments in most EU states. In recent years, energy security has returned as a major policy objective in the context of rising world market prices for energy, gas crises in Europe and predicted 'supply-side crunches' (IEA, 2007). Thus, renewable energy is enjoying a renaissance with rising awareness of its potential economic and social benefits.

While energy security and environmental concerns have motivated national efforts to accelerate renewable energy, advancing a policy framework at EU level has to be seen against the backdrop of the EU's longer-term ambition to promote liberalised and integrated energy markets. New problems were thus viewed through the prism of existing competences, namely, the EU's commitment to the four freedoms. Although energy was not originally subject to the Internal Market White Paper (COM(85) 310), the Commission turned its attention to the liberalisation of energy markets as early as 1988 (COM(88) 238). In the following years, the Commission and its Energy Commissioner played a key role as policy entrepreneurs (Nylander, 2001) in developing a far-reaching proposal for an internal market in gas and electricity (COM(91) 548). In so doing, the Commission managed to reconcile the principles of supply security and market liberalisation (McGowan, 2008: 94) by reframing electricity as an 'open market commodity', the trade in which could be facilitated through neoliberal deregulation (Nylander, 2001: 297). This formed an additional rationale for stronger EU policy intervention in national energy affairs, and helped to unite various parts of the Commission. For instance, while traditional views on electricity supply as a public service issue resided in DG Energy, deregulationist ideas were cultivated in DG Competition (Nylander, 2001). More importantly, the proposal implied a need 
for a level playing field upon which various energy sources could compete with each other.

Since the mid-1990s the Commission has claimed that this triad of energy policy objectives could be addressed simultaneously through the diversification of energy supply, deployment of renewable energy and liberalisation of energy

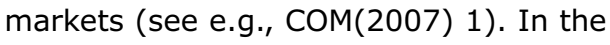
new draft Energy Strategy for Europe beyond 2010, currently under consultation, this line of reconcilement is supported, while concerns about low-carbon technology innovation, as addressed in the Strategic Energy Technology plan (COM(2009) 519), are gaining ground.

\section{NATIONAL OR EUROPEAN INTERESTS: POLICY COORDINATION OR REGULATORY HARMONISATION?}

After having worked out what problem(s) to address, governors have to decide at which level to act. Here, the main choice in the EU is between acting nationally or locally (e.g., guided by the principle of subsidiarity) or at higher levels, for example, regionally or at the global level. There are several level and scale dilemmas buried away in this choice: greater local diversity may offer more opportunities for experimentation and bottom-up learning, but fewer opportunities for learning across space. National decision makers may have more direct access to information, but run the risk of 'capture' by national interests. In practice, the choice between different political levels is seldom neither a binary one, as action may be required at several levels simultaneously, nor an entirely open choice as governors typically have stronger legal competence, or prior preference, to act at some levels than others.

In the EU, energy policy has traditionally been an issue of national competence. The Lisbon Treaty changes this, and the contents of both the 2008

\section{'In many ways, the new RES Directive can be understood as a half-way house between policy coordination and deep harmonisation'.}

climate-energy package and the new EU energy strategy indicate how the contours of a common energy policy are slowly emerging. Greater integration has, however, only been reached through a very slow and stepwise coordination of national energy policies. The seeds of an RES policy at the EU level are to be found in the 1997 White Paper and the RES-E and Biofuels Directives. Prior to 1997, energy insecurity concerns were simply not acute enough to trigger the development of a more coordinated approach.

The emergence, first, of environmental and, then, more specific climate change concerns spurred support for greater EU involvement, but only generated weakly coordinated policies. It was not until the Commission creatively exploited the internal market objectives that sufficiently strong political support for deeper integration and harmonisation emerged, in order to ensure compatibility with liberalised energy markets.

In one sense, then, an underlying choice has gradually been made to develop RES policy at the EU level. Common policy objectives have been adopted of a progressively more binding nature. However, the debates surrounding the choice of policy mechanisms and the 2009 RES Directive demonstrate the continuing salience of dilemmas related to the level and scale of governance. Therefore, while harmonisation of support mechanisms is regarded a long-term objective, the Commission have found it too early, given factual variations in resource availability and institutional capacity among 
states (SEC(2008) 57). In many ways, the new RES Directive can be understood as a half-way house between policy coordination and deep harmonisation. For instance, the efforts to advance a standardised GO regime very much implied a first step towards an EU-wide tradeable certificate scheme (Nilsson et al, 2009). Between the two approaches to trade one intergovernmental (state level), the other cross-border (firm level) - prepared by the Commission, only the interstate approach was retained in the final Directive, due to opposition from countries with feed-in systems. Hence, while the provisions for 'statistical transfers' and for joint support schemes allow for bottom-up coordination of national policies, it does not amount to deep harmonisation. Despite this fact the EU policy has, nonetheless, contributed to a de facto convergence in national support mechanisms. The 2008 progress review (SEC (2008) 57) provided no reason to depart from the status quo, and in crafting the new RES Directive, the Commission did not push hard for further harmonisation, so as not to forestall Member State opposition in order to reach agreement in time before the 2009 European Parliament elections (Toke, 2008). But the perceived need to choose whether and how far to harmonise support mechanisms remains, a choice closely related to modes and instruments dilemmas, to which we now turn.

\section{POLICY INSTRUMENTS: A CONTESTED GROUND}

Governing always entails choices about how to act. A critical choice is between regulating a set of enforceable social norms hierarchically, incentivising certain behaviours through market-based instruments, or relying on more network-based modes to build trust and share capacity among private and public actors. Choosing which mode and instrument of gov- ernance to enact is closely related to concerns about policy effectiveness, cost-efficiency and legitimacy. As many policy interventions do invariably generate losers as well as winners, policy makers have a choice to make (deliberately or not) about which costs and benefits to take into account, how to allocate them and whether (and how) to compensate any losers. In governing renewable energy one can distinguish between two main policy strategies: early EU policies concentrated on 'soft' coordination via harmonised technological $R \& D$ policies to push new renewable energy technologies onto the market. Although this fostered early technological learning, it failed to increase deployment significantly. In the 1990s, national policy makers therefore tried to stimulate demand and pull renewables into the market by market-supporting mechanisms such as feed-in tariffs; quota obligations based on tradeable green certificates; tendering systems; and incentive-based systems (taxation, subsidies). Out of these, feed-in tariff systems and tradeable green certificate schemes have been most widely imposed. ${ }^{2}$

The foremost lesson regarding the promotion of renewable energy is that RES deployment is a long-term and evolutionary process that requires enduring policy support. Government policies such as $R \& D$, demonstration and investment support seem to have been the single most important factor behind, for example, the strong deployment of wind power in Germany (Jacobsson and Lauber, 2006). Similarly, studies of wind power in Denmark (e.g., Meyer, 2006; Agnolucci, 2007) and biomass energy in Finland and Sweden (e.g., Ericsson et al, 2004; Jacobsson, 2008) emphasise the importance of policy support and political stability. Taking technological maturity and different stages of development into account is further viewed as crucial. In 
general, investment grants seem suitable for immature technologies, whereas feedin tariffs seem most effective during the interim stage of market introduction. By contrast, premium feed-in tariffs or quota obligations based on tradeable certificates could be appropriate 'once the markets and technologies are sufficiently mature and market size is large enough to guarantee competition' (Resch et al, 2007: 42). Therefore, while loose forms of policy coordination were probably more appropriate during the early phases of technological and institutional learning, an EU-wide policy framework came to be viewed as necessary to ensure that RES made up a significant part of the energy mix. ${ }^{3}$

The EU has tried to render national policies more effective and economically efficient. The dominant support mechanisms delegate responsibilities from the state to the private sector and shift the burden from state budgets (i.e., tax payers) to energy consumers. This distributional feature has been largely overlooked in the debate about alternative policy instruments. While tradeable certificates are often presented as though they are the most market-oriented measure, this neglects that competition also takes place in price-based feed-in systems. In fact, both systems are marketbased; the difference lies in the means used to determine prices and quantities (Hvelplund, 2005). Both systems can, if designed properly, effectively promote renewables (Hvelplund, 2005; van der Linden et al, 2005), but a range of empirical studies indicate that feed-in tariffs have induced the most rapid and cost-effective deployment (e.g., Held et al, 2006; Resch et al, 2007; SEC (2008) 57). Because of its long-term minimum prices, feed-in tariff systems provide more stability and greater investor security than tradeable certificates schemes (Mitchell et al, 2006). As this is a more critical problem for independent small investors, the RES industry has tended to prefer feed-in tariffs, in opposition to incumbent power utilities.

These issues about instrument choice have, since the late $1990 \mathrm{~s}$, generated a fierce debate in Brussels and a formidable struggle between two main camps of interests, cutting across the European energy industry and the Member States. The independent RES industry points out the advantages of more diversified energy supplies, such as economic innovation, job creation and energy security. By contrast, major electricity suppliers subscribe to the view that the high cost of investing in new RES requires mechanisms stimulating market-based competition. While the power industry emphasises cost-effectiveness as a main concern, the RES industry addresses existing market distortions and calls for greater competition and fair access to energy markets. Unsurprisingly, the RES industry advocates feed-in tariff schemes, while the power industry tradeable green certificates (Toke, 2008). The Commission has, with support from 'deregulationist' states (e.g., the UK), endorsed certificate schemes as being better at promoting competition between energy sources, and hence more compatible with liberalised energy markets. Irony of ironies, the burgeoning RES industry has concurrently grown stronger and, together with feed-in states such as Germany and Spain, successfully resisted every attempt to impose such a pan-European policy regime. This has forced the Commission to defuse its ambitions to harmonise policy mechanisms, mustering instead on other issues.

\section{SECURING COMPLIANCE: ENCOURAGING OR ENFORCING?}

Crafting policies is one thing, but making states comply is another. Once enacted, policies have to be implemented and 
enforced. The main governance dilemma here revolves around achieving coordination through relatively non-hierarchical norms or through hierarchical means. Examples of the former are reporting requirements, shaming and blaming. Examples of the latter are fines and legal sanctions. These issues are not only of a technical nature but are highly political issues. In practice, a balance has to be struck between the two, so that systems with clear penalties also develop less coercive elements, and vice versa. Looking at the previous RES-E and Biofuels Directives, the EU did try to design them to ensure compliance. The RES-E Directive obliged Member States to evaluate how well their regulatory frameworks facilitate compliance, required them to streamline administrative procedures and ensure access to the grid for renewable electricity generators. The national targets for 2010 were only indicative, but the Commission has nevertheless been able to use them as justification for legal action against laggard states. If Member States failed to comply with their target without 'justified reasons', the Directive entitled the Commission to present 'appropriate proposals' (e.g., mandatory targets). The Commission hesitated to do this before the draft RES Directive was issued in 2008, although Member States have varied greatly in their implementation and that reforming administrative rules for licensing, planning and grid access have proved to be especially troublesome (IEA, 2008).

The 2009 RES Directive thus enhances the implementation measures, although still lacking stringent enforcement mechanisms such as financial penalties. Most importantly, it contains legally binding targets for the Member States. It sets out an indicative trajectory towards 2020 for each country and provides for regular reviews to encourage compliance. In 2010, Member States issued national action plans outlining 'adequate measures' to meet their targets, with biannual progress reviews. The legally binding nature of the targets implies, in principle, that infringement proceedings may be initiated against laggard states. But more likely is, given the informal norm of negotiated enforcement in the EU, that they will be obliged to submit amended plans to remedy any shortfalls.

\section{CONCLUSIONS}

The story of renewable energy policy at the EU level is a story about a slow, and at times cumbersome, crafting of a policy domain. Along the protracted way towards a common RES policy framework, the EU has had to grapple with a range of governance dilemmas. The EU's capacity to govern has developed slowly because energy supply remains a key area of national interest. In the 1970 s and 1980s, renewable energy was not deemed important enough to justify deeper EU-level coordination, and hence integration was held back by Member States' unwillingness to enable Brussels to govern in this field. It was not until the liberalisation of European electricity markets in the latter half of the 1990s, that a clear EU-level rationale for harmonising national RES policies emerged as an extension to the integration of electricity distribution. Hence, policies for the promotion of renewable energy have developed gradually from loose forms of interstate cooperation, to deeper forms of policy coordination and regulatory harmonisation. The process started slowly via support to R\&D and demonstration, important for technological learning and for securing early acceptance and legitimacy of subsequent policy interventions. The more explicit EU RES policy dates from the mid-1990s, when ALTENER was introduced as the first specific EU-wide initiative, followed by the first compre- 
hensive RES policy strategy in 1997, and later on by a series of regulatory initiatives leading up to the recent climate and energy package.

The Commission's ability to develop a harmonised framework has been hampered by conflicts between the EU institutions, Member States and industrial and environmental stakeholders. In essence, the overriding governance challenge has been to balance various interests and strike the right chord among three different policy objectives (competitiveness, energy security and climate change mitigation) and competing values (market efficiency versus deployment effectiveness). Concerns about energy insecurity and climate change have given the promotion of renewable energy a strong push at the national level, but have not carried the same weight at the EU level. The internal energy market has provided the primary justification for deeper coordination and is the dominant 'problem' that EU RES policy seeks to address. Therefore, while renewable energy and climate change policies developed contemporaneously in the EU, a key driver of the former has been the concern for the internal market, and not the concern about an impending climate catastrophe. This explains why the Commission has continued to advocate harmonisation in the general sense, without coming down firmly in favour of one particular model or mechanism. The debates triggered by the 2009 RES Directive brought these ongoing issues back into sharp focus. However, compared with earlier, the additional presence of energy insecurity and climate change concerns made it considerably easier for the Commission to make the case for more ambitious and, perhaps even more crucially, binding targets.

Taken together, these concerns provide a propitious case for continued integration that, eventually, may pave the '...while renewable energy and climate change policies developed contemporaneously in the EU, a key driver of the former has been the concern for the internal market, not concern about an impending climate catastrophe'.

\section{'...it is doubtful whether the Member States and EU citizens are yet prepared to accept further efforts in that direction towards deeper integration of energy policy'.}

way for harmonisation not only of energy market regulations, but also national mechanisms supporting renewable energy. However, that remains to be seen; after all the resistance to a harmonised policy regime seems stronger than ever. Continued ambitions to deploy RES at a vast scale will require further policy and institutional reforms at both national and EU level, and the Commission currently tries to exploit the provisions made in the Lisbon Treaty to advance a common energy policy strategy. But it is doubtful whether the Member States and their citizens are yet prepared to accept further efforts in that direction towards deeper integration of energy policy. Thus, the RES policy looks set to continue provoking challenging governance dilemmas for the EU. 


\section{Notes}

1 The article is based on research conducted within the ADAM project (www.adamproject.eu) as presented in Jordan et al (2010).

2 In eighteen Member States the main support mechanism is feed-in tariffs or feed-in premiums (pricebased). In seven Member States, tradeable green certificates/quota systems (quantity-based) have been introduced (SEC(2008) 57; IEA, 2008).

3 The EU deployment of RES is rapidly growing, although when viewed against the agreed targets (12 per cent by $2010 ; 20$ per cent by 2020) performance is insufficient. In 2008, the EU RES share was 10.3 per cent of final energy consumption compared to 8.5 per cent in 2005 and 6.3 per cent in 1991 (COM(2008) 30; SEC(2011) 130). Renewable power increased to 16.6 per cent of gross electricity consumption and biofuels to 3.5 per cent of transport fuel consumption in 2008 (SEC(2011) 130), still short of the indicative 2010 targets ( 21 per cent; 5.75 per cent). The Commission estimates that Member States will reach only 19 per cent and 4 per cent, respectively, by 2010 but considers the new RES Directive to be satisfactory to support ongoing growth in wind and solar energy, although additional efforts are required to accelerate biomass energy (COM(2009) 192).

\section{References}

Agnolucci, P. (2007) 'Wind electricity in Denmark: A survey of policies, their effectiveness and factors motivating their introduction', Renewable and Sustainable Energy Reviews 11(5): 951-963.

Ericsson, K., Huttunen, S., Nilsson, L.J. and Svenningsson, P. (2004) 'Bioenergy policy and market development in Finland and Sweden', Energy Policy 32(15): 1707-1721.

European Commission (2010) 'Summary of the member state forecast documents', available at: http:// ec.europa.eu/energy/renewables/transparency_platform/doc/0_forecast_summary.pdf, accessed 10 June 2010.

Held, A., Ragwitz, M. and Haas, R. (2006) 'On the success of policy strategies for the promotion of electricity from renewable energy sources in the EU', Energy and Environment 17(6): 849-868.

Hildingsson, R., Stripple, J. and Jordan, A. (2010) 'Renewable Energies: A Continuing Balancing Act?', in A. Jordan, D. Huitema, H. van Asselt, T. Rayner and F. Berkhout (eds.) Climate Change Policy in the European Union: Confronting the Dilemmas of Adaptation and Mitigation? Cambridge: Cambridge University Press, pp. 103-124.

Hvelplund, F. (2005) 'Renewable Energy: Political Prices of Political Quantities', in V. Lauber (ed.) Switching to Renewable Power: A framework for the 21st Century, London: Earthscan, pp. 228-245.

IEA. (2007) World Energy Outlook 2007, Paris: IEA.

IEA. (2008) Deploying Renewables: Principles for Effective Policies, Paris: IEA.

Jacobsson, S. (2008) 'The emergence and troubled growth of a "biopower" innovation system in Sweden', Energy Policy 36(4): 1491-1508.

Jacobsson, S. and Lauber, V. (2006) 'The politics and policy of energy system transformation: Explaining the German diffusion of renewable energy technology', Energy Policy 34(3): 256-276.

Johnston, A., Neuhoff, K., Fouquet, D., Ragwitz, M. and Resch, G. (2008) 'The proposed new EU renewables directive: Interpretation, problems and prospects', European Energy and Environmental Law Review 17(3): 126-145.

Jordan, A., Huitema, D., van Asselt, H., Rayner, T. and Berkhout, F. (2010) Climate Change Policy in the European Union: Confronting the Dilemmas of Adaptation and Mitigation? Cambridge: Cambridge University Press.

Lauber, V. (2005) 'European Union Policy towards Renewable Power', in V. Lauber (ed.) Switching to Renewable Power: A Framework for the 21st Century, London: Earthscan, pp. 203-216.

McGowan, F. (2008) 'Can the European Union's market liberalism ensure energy security in a time of 'economic nationalism?' Journal of Contemporary European Research 4(2): 90-106.

Meyer, N.I. (2006) 'Influence of government policy on the promotion of wind power', International Journal of Global Energy Issues 25(3/4): 204-218.

Mitchell, C., Bauknecht, D. and Connor, P.M. (2006) 'Effectiveness through risk reduction: A comparison of the renewable obligation in England and Wales and the feed-in system in Germany', Energy Policy 34(3): 297-305.

Nilsson, M., Nilsson, L.J. and Ericsson, K. (2009) 'The rise and fall of GO trading in European renewable energy policy: The role of advocacy and policy framing', Energy Policy 37(11): 4454-4462. 
Nylander, J. (2001) 'The construction of a market: A frame analysis of the liberalisation of the electricity market in the European Union', European Societies 3: 289-314.

Resch, G., Faber, T., Haas, R., Huber, C., Ragwitz, M. and Held, A. (2007) Recommendations for Implementing Effective \& Efficient Renewable Electricity Policies - Report of the IEE project OPTRES, Vienna: Vienna University of Technology.

Rowlands, I.H. (2005) 'The European directive on renewable electricity: Conflicts and compromises', Energy Policy 33(8): 965-974.

Toke, D. (2008) 'The EU renewables directive: What is the fuss about trading?' Energy Policy 36(8): 3001-3008.

van der Linden, N.H., Uyterlinde, M.A., Vrolijk, C., Nilsson, L.J., Khan, J., Åstrand, K., Ericsson, K. and Wiser, R. (2005) Review of international experience with renewable energy obligation support mechanisms, ECN report C-05-025, Petten: ECN.

\section{About the Authors}

Roger Hildingsson is a Ph.D. student in Political Science at Lund University, Sweden.

Johannes Stripple is Researcher and Senior Lecturer in the Department of Political Science at Lund University, Sweden.

Andrew Jordan is Professor of Environmental Politics in the School of Environmental Sciences at the University of East Anglia, Norwich, United Kingdom. 